\title{
Isolation, Characterisation and Antibiotic Susceptibility of Staphylococcal Isolates with Special Reference to Methicillin-Resistant Staphylococcus aureus From the Anterior Nares of Healthcare Workers in a Tertiary Healthcare Centre
}

\author{
Mukul Chaurasia, ${ }_{1}^{1}$ Neha Agrawal, ${ }_{1}^{1}$ Ankita Chourasia, ${ }^{2}$ Monica Bhatnagar, ${ }^{2}$ Geeta Parihar, \\ Vijaylatha Rastogi, ${ }^{1}$ Amit Tak ${ }^{3}$
}

\section{Abstract}

Background: Staphylococcus aureus (S. aureus) and its resistant form methicillinresistant $S$. aureus (MRSA) is one of the most common nosocomial pathogens causing a wide range of infections in humans. The anterior nares are the main ecological niche for $S$. aureus. Nasal carriage of $S$. aureus acts as an important reservoir of infection among the colonised healthcare workers and they transmit the infection to the community. The aim of the present study was to estimate the nasal colonisation of $S$. aureus (with special reference to MRSA) in healthcare workers (doctors and nursing staff) and its antibiotic susceptibility pattern.

Methods: A descriptive study was planned in the Department of Microbiology, JLN Medical College, Ajmer (Rajasthan, India) after due approval from the institutional ethics committee. A total of 170 healthcare workers of either sex aged between 18 to 60 years were screened for $S$. aureus. Identification was done using standard microbiological techniques, by studying their morphology, colony and biochemical characteristics. MRSA was detected by cefoxitin disc diffusion test, oxacillin disc diffusion test, minimum inhibitory concentration (MIC) of oxacillin by E-test and oxacillin screen agar test. The observations were described in proportions and Chisquared test was used to find independence. Statistical significance was considered at $5 \%$.

Results: Among 170 samples, 159 (93.53\%) samples (50 doctors and 109 nursing staff) had staphylococci colonisation. Among these 159 isolates, 34 (21.38\%) were S. aureus. Further, 8 (5.03 \%) S. aureus isolates were resistant to both cefoxitin and oxacillin and had oxacillin MIC values $\geq 4 \mu \mathrm{g} / \mathrm{mL}$ and were considered MRSA. All the MRSA were detected in the nursing staff (males: $5.50 \%$, females: $1.83 \%$ ). All $S$. aureus and MRSA isolates were found sensitive to linezolid, vancomycin and mupirocin (minimum inhibitory concentration $\leq 4 \mu \mathrm{g} / \mathrm{mL}$ ).

Conclusion: Screening and treatment of healthcare workers colonised with MRSA should be an important component of hospital infection control policy. These measures will prevent spread of infection to patients and the community and thereby reduce the morbidity, mortality and healthcare costs associated with nosocomial infections.

Key words: Antibiotic susceptibility pattern; Healthcare workers; Methicillin-resistant Staphylococcus aureus; Minimum inhibitory concentration; Nosocomial infections.
(1) Department of Microbiology, JLN Medical College, Ajmer, Rajasthan, India.

(2) Department of Microbiology, Maharshi Dayanand Saraswati University, Ajmer, Rajasthan, India.

(3) ICMR - National Centre for Disease Informatics and Research, Bengaluru, Karnataka, India.

Correspondence:

AMIT TAK

E: dramittak@gmail.com

ARTICLE INFO

Received: 6 March 2021

Revision received: 29 March 2021

Accepted: 29 March 2021

Copyright $\odot 2021$ Chaurasia et al. This is an open access article distributed under the Creative Commons Attribution License (CC BY), which permits unrestricted use, distribution, and reproduction in any medium, provided the original work is properly cited. This article should be cited as follows: Chaurasia M, Agrawal N, Chourasia A, Bhatnagar M, Parihar G, Rastogi V, et al. Isolation, characterisation and antibiotic susceptibility of staphylococcal isolates with special reference to methicillin-resistant Staphylococcus aureus from the anterior nares of healthcare workers in a tertiary healthcare centre. Scr Med 2021 Jun;52(2):85-95. 


\section{Introduction}

Staphylococci are ubiquitous colonisers of skin and mucosa and highly successful opportunistic pathogens. S. aureus is one of the most harmful species of staphylococci encountered. ${ }^{1}$ It is one of the most pathogenic bacterial species in humans causing a wide variety of infections ranging from mild skin and soft tissue infections (furuncles, carbuncles etc) to severe life-threatening infections like chronic bone infections, necrotising pneumonia, bacteraemia, septicaemia, acute endocarditis, myocarditis, pericarditis, osteomyelitis, encephalitis, meningitis, chorioamnionitis, mastitis, toxic-shock syndrome, scalded skin syndrome ${ }^{2-5}$ and intravenous infections or at other sites where tubes enter the body (indwelling medical devices). ${ }^{6}$ It is distinct from coagulase-negative staphylococci (CoNS) eg, S. epidermidis, and is more virulent despite phylogenetic similarities between them. ${ }^{7,8}$

The key characteristics of $S$. aureus are colony pigmentation, production of free coagulase, clumping factor, protein-A, heat-stable nuclease, lipase and acid production from mannitol. ${ }^{3}$ The species aureus, refers to those colonies that often have a golden colour when grown on solid media, while CoNS form pale, translucent, white colonies.

Staphylococcal infections occur frequently in hospitalised patients and have severe consequences, despite antibiotic therapy. ${ }^{9}$ S. aureus are generally susceptible to $\beta$-lactam antibiotics, but extensive use of this class of drugs has led to increasing emergence of resistant strains. ${ }^{10}$ The most notable example is the emergence of methicillin-resistant Staphylococcus aureus (MRSA), which was reported just one year after the introduction of methicillin. ${ }^{11}$ Also known as "a superbug", MRSA has become a major problem in most medical institutions because it is creating life-threatening situations. ${ }^{11}$ MRSA is a major healthcare-associated (HA-MRSA) as well as a community-associated (CA-MRSA) infection. ${ }^{6}$

Healthcare workers (HCWs) constitute an important reservoir of $S$. aureus. Nasal carriage of $S$. aureus acts as an important reservoir of infection among those colonised, who may then transmit the infection to co-workers and others in the community. ${ }^{12}$ Approximately $20 \%$ of individuals are persistent carriers, about $60 \%$ are intermittent carriers and $20 \%$ almost never carry $S$. aureus. ${ }^{13}$ Several studies have reported that the rate of the nasal carriage of $S$. aureus among the HCWs ranges from $16.8 \%$ to $56.1 \% .{ }^{14-17}$ Studies conducted in different hospital settings worldwide including India, have reported the prevalence of MRSA in HCWs in the range of $5.8 \%$ to $17.8 \%{ }^{18-22,9,12}$ The growing problem in India is that MRSA prevalence has increased from $12 \%$ to $80.83 \%{ }^{23}$ The healthcare workers who are found to be colonised with $S$. aureus are advised to apply mupirocin ointment in their anterior nares and they should be retested for the nasal carriage of $S$. aureus after 3 months of treatment. ${ }^{9}$

The aim of the present study was to estimate the nasal carriage and antimicrobial susceptibility pattern of $S$. aureus and MRSA isolates among the HCWs in a tertiary healthcare centre. The prevalence of $S$. aureus carriers and its resistance to methicillin will help the institution develop a better MRSA infection control policy.

\section{Methods}

This descriptive study was carried out in the Department of Microbiology, Jawahar Lal Nehru (JLN) Medical College and Hospital, Ajmer, Rajasthan, India from November 2016 to December 2017. The study was approved by the Ethics Committee of JLN Medical College, Ajmer and written informed consent was obtained from all the participants.

A total of 170 HCWs aged 18 to 60 years, actively involved in healthcare provision in different departments of JLN Medical College were enrolled for the study. Each participant was interviewed using a questionnaire on general socio-demographic information, personal details and clinical symptoms. Exclusion criteria included healthcare workers not actively involved in patient care or those suffering from underlying chronic disease or respiratory tract infections, with a history of recent hospitalisation, intake of broad-spectrum antibiotics, fever or those who did not consent.

\section{Sample collection}

Nasal swabs from the anterior nares of both nostrils were collected using sterile cotton swabs with transport tubes. A swab pre-moistened with sterile saline was inserted approximately $1-2 \mathrm{~cm}$ 
into the anterior nares and slowly rotated against the nasal mucosa five times. ${ }^{24}$ Both nostrils were sampled using the same swab. After collection, the swabs were re-inserted in the transport tubes, labeled properly and transported to the laboratory within 30 minutes of collection for further processing.

\section{Sample processing}

All the specimens were inoculated on $5 \%$ sheep blood agar, nutrient agar and MacConkey agar (HiMedia Laboratories Pvt Ltd Mumbai, Maharashtra, India) and incubated at $37{ }^{\circ} \mathrm{C}$ for 24 hours. After incubation, identification of genus Staphylococcus was done using standard microbiological techniques, by studying their morphology, colony characteristics and biochemical properties. Staphylococci were identified as Gram positive, catalase positive, furazolidone susceptible and bacitracin-resistant. $S$. aureus colonies were further identified as slide and tube coagulase positive, polymyxin B-resistant and mannitol fermenting giving yellow pigmentation on mannitol salt agar.

\section{Antimicrobial susceptibility testing (AST)}

Antibiotic susceptibility was studied by modified Kirby-Bauer disc diffusion method ${ }^{25}$ on Mueller Hinton Agar plates (120 mm diameter) using commercially available antibiotic discs (HiMedia Laboratories Pvt. Ltd. Mumbai, Maharashtra, India): penicillin G (10 units), cephalexin $(30 \mu \mathrm{g})$, cefoxitin $(30 \mu \mathrm{g})$, oxacillin $(1 \mu \mathrm{g})$, gentamicin $(10$ $\mu \mathrm{g})$, netilmicin $(30 \mu \mathrm{g})$, ciprofloxacin $(5 \mu \mathrm{g})$, ofloxacin $(5 \mu \mathrm{g})$, levofloxacin $(5 \mu \mathrm{g})$, erythromycin (15 $\mu \mathrm{g})$, clindamycin $(10 \mu \mathrm{g})$, tetracycline $(30 \mu \mathrm{g})$, cotrimoxazole $(25 \mu \mathrm{g})$, quinupristin dalfopristin $(15 \mu \mathrm{g})$, vancomycin $(30 \mu \mathrm{g})$, linezolid $(30 \mu \mathrm{g})$, cephalothin $(30 \mu \mathrm{g})$, amoxicillin/clavulanic acid (co-amoxiclav, $30 \mu \mathrm{g}$ ) and ampicillin $(10 \mu \mathrm{g})$. Zone diameter interpretation for determining sensitive, intermediate or resistant isolates was done as per CLSI 2016 guidelines. ${ }^{26}$

\section{Detection of methicillin-resistant Staphylo- coccus aureus (MRSA)}

All confirmed $S$. aureus isolates were tested for detection of methicillin resistance by four different methods. Kirby-Bauer disc diffusion method using oxacillin $1 \mu \mathrm{g}$ and cefoxitin $30 \mu \mathrm{g}$ discs (HiMedia Laboratories, Mumbai, Maharashtra, India), ${ }^{27}$ minimum inhibitory concentration (MIC) testing of oxacillin by E-test and growth on Oxacillin Resistance Screening Agar (ORSA) plates ${ }^{28}$ as per CLSI 2016 guidelines. ${ }^{26}$ Zone of inhibition of size $\leq 10 \mathrm{~mm}$ was taken as resistant, 11-12 $\mathrm{mm}$ as intermediate and $\geq 13 \mathrm{~mm}$ as sensitive for oxacillin. Zone of inhibition of size $\leq 21 \mathrm{~mm}$ was taken as resistant, and $\geq 22 \mathrm{~mm}$ as sensitive for cefoxitin. On oxacillin E-test, an MIC of $\leq 2 \mu \mathrm{g} / \mathrm{mL}$ was considered susceptible and $\geq 4 \mu \mathrm{g} / \mathrm{mL}$ as resistant. Any growth on oxacillin screen agar was considered as methicillin (oxacillin) resistant.

\section{Detection of mupirocin-resistant Staphylo- coccus aureus}

The MIC of mupirocin for isolation of $S$. aureus (Mupirocin resistance) was determined by Epsilometer test (E-test) using HiMedia, mupirocin strip (range 0.064-1024 $\mu \mathrm{g} / \mathrm{mL}$ ) and interpreted as per CLSI 2016 guidelines. ${ }^{26}$ Isolates with mupirocin MICs $\geq 512 \mu \mathrm{g} / \mathrm{mL}$ were considered as high-level resistant (MuH), those with MICs 8-256 $\mu \mathrm{g} / \mathrm{mL}$ were considered as low-level resistant (MuL), and with $\leq 4 \mu \mathrm{g} / \mathrm{mL}$ were considered as mupirocin sensitive.

\section{Statistical analysis}

The descriptive statistics for quantitative data was expressed as mean and standard deviation and qualitative data was expressed as proportions. Chi-squared test was used to find independence of attributes at $5 \%$ level of significance $(\alpha=0.5)$. The JASP 0.11.1.0 statistical package was used for statistical analysis.

\section{Results}

In the present study, nasal swabs were randomly collected from a total of 170 HCWs from various clinical departments and screened for the study of Staphylococcus colonisation. Out of a total of 170 samples, 159 (93.53\%) had staphylococci colonisation. Of these $159 \mathrm{HCWs}$, with age group ranging between 18 to 60 years, $99(62.26 \%)$ were males and $60(37.74 \%)$ were females. The colonisation rate was $31.45 \%, 34.59 \%, 18.24 \%$ and $15.72 \%$ in the age groups '18-30', '31-40', '41-50' and '5160 ' years, respectively (Figure 1).

From these 159 subjects, 50 were doctors and 109 were nursing staff. Of the 50 doctors, 37 (74\%) were males and 13 (26\%) were females. Among the 109 nursing staff, 62 (56.88 \%) were males 
and $47(43.12 \%)$ were females. The maximum carriage rate in doctors was observed in the age group 31-40 years ie, $60 \%$, where $50 \%$ were males and $10 \%$ were females. In the nursing staff group, maximum carriage was seen in 18-30 years age group where $20.18 \%$ were males and 18.35 $\%$ were females accounting for a total of $38.53 \%$ carriage rate in their group (Figure 1).

In the present study Staphylococcus colonisation was detected in 159 (93.53\%) healthcare workers which comprised 34 (21.38\%) S. aureus and 125 (78.61\%) CoNS isolates. Dual colonisation with $S$. aureus and CoNS was observed in 10 samples. The carriage rate of $S$. aureus was significantly higher in nursing staff $(26.60 \%)$ as compared to doctors $(10 \%)\left(\chi^{2}=5.62, p=0.018\right)$. Professors/associate professors/assistant professors and resident doctors were found to have $S$. aureus nasal carriage rate $16.67 \%$ and $7.89 \%$, respectively (Figure 1 ).
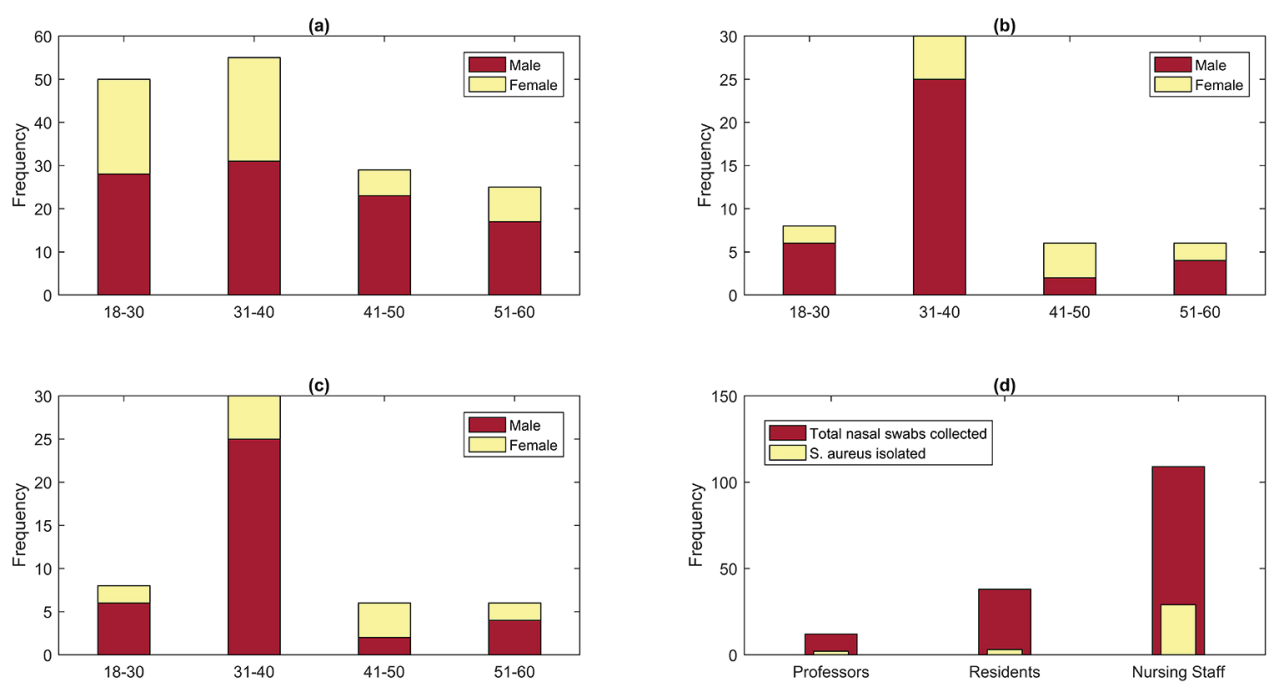

Figure 1: Stacked bar plots showing demographic profile (a) Age wise gender distribution of all healthcare workers ( $n=159)$, (b) age-wise gender distribution of doctors $(n=50)$, (c) age-wise gender distribution of nursing staff $(n=109)$, (d) Total number of nasal swabs collected and $S$. aureus isolated in healthcare workers $(n=159)$

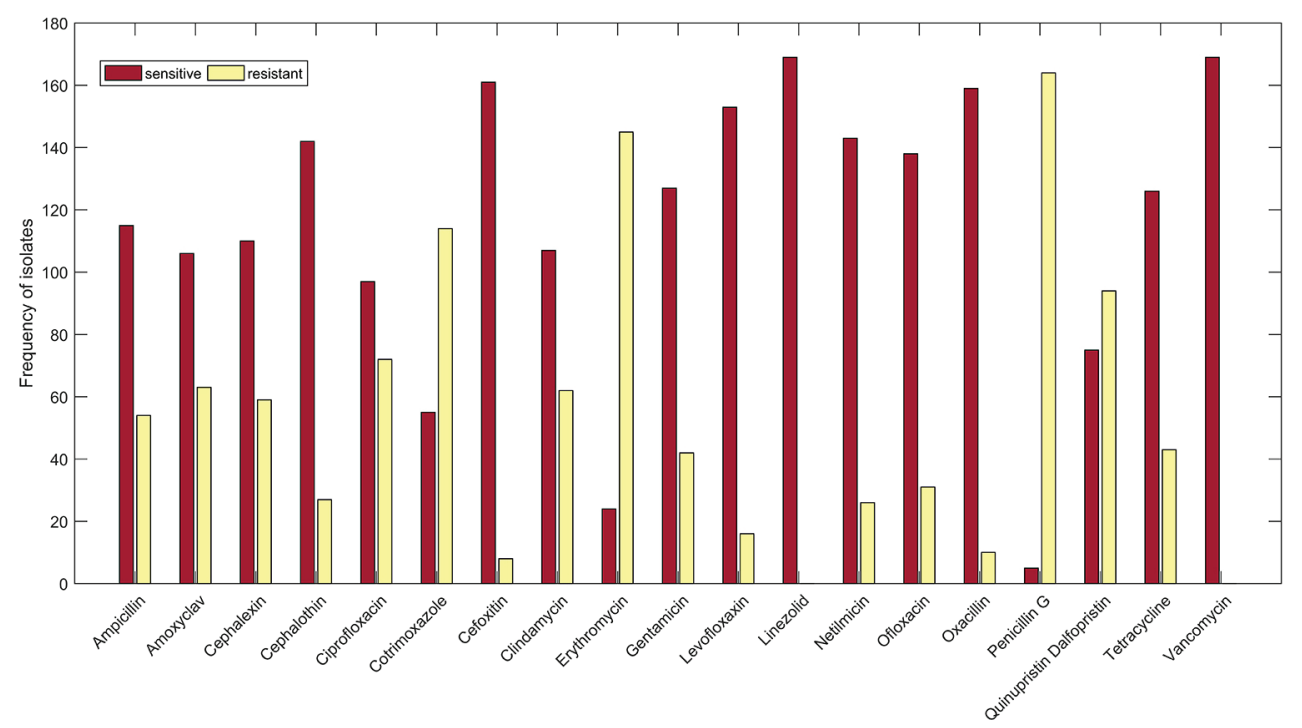

Figure 2: Bar plots showing antimicrobial sensitivity pattern of Staphylococcus isolates by modified Kirby-Bauer disc diffusion method $(n=169)$ 


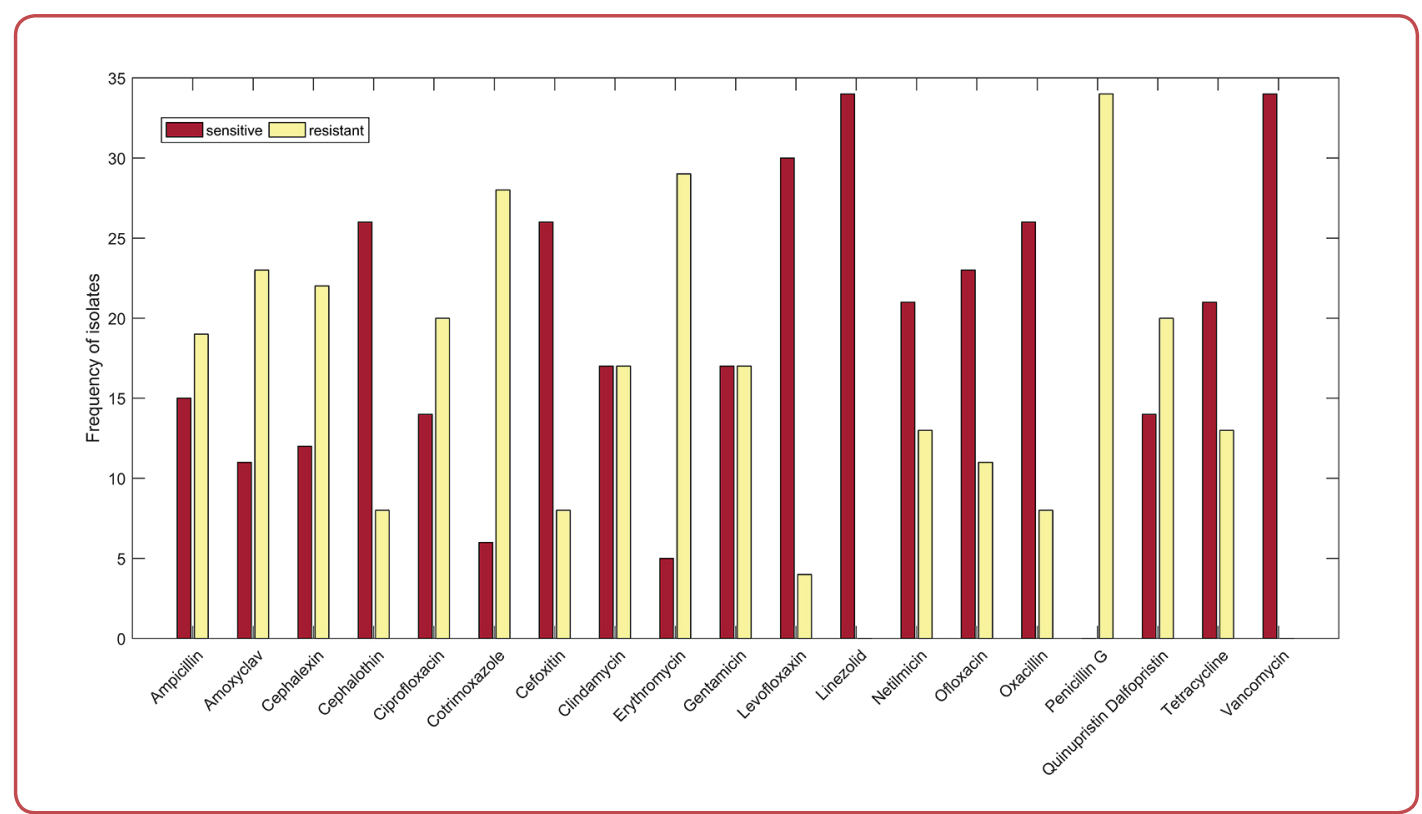

Figure 3: Bar plots showing antimicrobial sensitivity pattern of $S$. aureus isolates by modified Kirby-Bauer disc diffusion method $(n=34)$

Antimicrobial sensitivity pattern of Staphylococcus isolates by disc diffusion method is shown in Figure 2 . Ten subjects had concomitant colonisation of $S$. aureus and CoNS. Therefore, antimicrobial susceptibility testing was done for 169 Staphylococcus isolates.

Among the antibiotics tested, all the staphylococcal isolates were susceptible only to linezolid and vancomycin (100\%). Maximum resistance was shown to penicillin G (97.49\%). Resistance to cefoxitin and oxacillin was $4.73 \%$ and $5.92 \%$, respectively.

All the $S$. aureus isolates were found to be susceptible to linezolid and vancomycin (100\%). All $S$. aureus isolates showed complete resistance to penicillin G (100\%). Extremely low susceptibility was shown for erythromycin $(17.71 \%)$ and cotrimoxazole (17.65\%). Resistance to cefoxitin and oxacillin was $23.53 \%$ (Figure 3 ).

Detection of MRSA was done by four different phenotypic methods. Among the 34 S. aureus isolates studied, 8 isolates $(23.53 \%)$ were found to be MRSA. While in oxacillin screen agar testing, 6 $(17.65 \%)$ isolates were found to be MRSA. No isolate showed intermediate resistance. Thus, out of 34 S. aureus isolates, 8 (23.53\%) were MRSA and $26(76.47 \%)$ were methicillin sensitive $S$. aureus (MSSA) (Table 1). One MRSA isolate showed resistance to vancomycin disc on AST. However due to limited resources, further testing of this isolate
Table 1: Comparison of different phenotypic methods for detection of methicillin resistance in $S$. aureus isolates $(n=34)$

\begin{tabular}{|c|c|c|c|c|}
\hline \multirow[b]{2}{*}{ S. aureus } & \multicolumn{4}{|c|}{ Tests used for detection of MRSA } \\
\hline & $\begin{array}{l}\text { Oxacillin }(1 \mu \mathrm{g}) \\
\text { disc diffusion }\end{array}$ & $\begin{array}{l}\text { Cefoxitin }(30 \mu \mathrm{g}) \\
\text { disc diffusion }\end{array}$ & $\begin{array}{l}\text { Oxacillin } \\
\text { screen agar }\end{array}$ & $\begin{array}{l}\text { Oxacillin MIC } \\
\text { by E-test }\end{array}$ \\
\hline $\begin{array}{l}\text { Methicillin-resistant } \\
\text { S. aureus (MRSA) }\end{array}$ & $8(23.53)$ & $8(23.53)$ & $6(17.65)$ & $8(23.53)$ \\
\hline $\begin{array}{l}\text { Methicillin-sensitive } \\
\text { S. aureus (MSSA) }\end{array}$ & $26(76.47)$ & $26(76.47)$ & $28(82.35)$ & $26(76.47)$ \\
\hline
\end{tabular}

by MIC testing of vancomycin using agar dilution method (recommended by CLSI) to determine it as vancomycin-resistant, intermediate or sensitive could not be carried out.

In the present study, the $8 \mathrm{~S}$. aureus isolates that were resistant to both cefoxitin and oxacillin had oxacillin MIC values $\geq 4 \mu \mathrm{g} / \mathrm{mL}$ (Table 2 ). There were no isolates found resistant to cefoxitin and intermediate resistance to oxacillin at the same

Table 2: Comparison of cefoxitin and oxacillin disc diffusion tests with minimum inhibitory concentration (MIC) of oxacillin by E-test method $(n=34)$

\begin{tabular}{lcc}
$\begin{array}{l}\text { Results of oxacillin and } \\
\text { cefoxitin disc diffusion }\end{array}$ & $\begin{array}{c}\text { MIC of oxacillin } \\
(\mu \mathrm{g} / \mathrm{mL})\end{array}$ & $\begin{array}{c}\text { No. of isolates } \\
(\%)\end{array}$ \\
\hline $\begin{array}{l}\text { Resistant to both } \\
\text { cefoxitin and oxacillin }\end{array}$ & $\geq 4$ & $8(23.53)$ \\
\hline $\begin{array}{l}\text { Resistant to cefoxitin and } \\
\text { intermediate resistant to oxacilln }\end{array}$ & $\geq 4$ & $0(0.0)$ \\
\hline $\begin{array}{l}\text { Resistance to cefoxitin and } \\
\text { sensitive to oxacillin }\end{array}$ & $\geq 4$ & $0(0.0)$ \\
$\begin{array}{l}\text { Sensitive to } \\
\text { cefoxitin and oxacillin }\end{array}$ & $<4$ & $26(76.47)$ \\
\hline
\end{tabular}

Note: percentage is shown in parenthesis 
Table 3: Nasal carriage of $S$. aureus and MRSA among various healthcare workers $(n=34)$

\begin{tabular}{lccc}
\hline Healthcare workers & $\begin{array}{l}\text { No. of nasal } \\
\text { swabs collected }\end{array}$ & $\begin{array}{l}\text { No. of } \boldsymbol{S} \text {.aureus } \\
\text { isolated (\%) }\end{array}$ & $\begin{array}{l}\text { No. of MRSA } \\
\text { isolated (\%) }\end{array}$ \\
\hline $\begin{array}{l}\text { Professors, Associate } \\
\text { Professors, Assistant } \\
\text { professors }\end{array}$ & 12 & $02(16.67)$ & $0(0.0)$ \\
\hdashline Resident doctors & 38 & $03(7.89)$ & $0(0.0)$ \\
\hline Nursing staff & 109 & $29(26.60)$ & $08(7.34)$ \\
\hdashline Total & 159 & $34(21.38)$ & $08(5.03)$ \\
\hline
\end{tabular}

Note: percentage is shown in parenthesis; $S$. aureus: Staphylococcus aureus; MRSA: methicillin-resistant Staphylococcus aureus

time. No isolate was found resistant to cefoxitin while being sensitive to oxacillin. $26 \mathrm{~S}$. aureus isolates that were sensitive to both oxacillin and cefoxitin by disc diffusion method had MICs $\leq 2$ $\mu \mathrm{g} / \mathrm{mL}$, indicating their susceptibility to oxacillin. Thus, out of 34 S. aureus isolates, $8(23.53 \%)$ were MRSA and the remaining 26 (76.47 \%) were oxacillin and methicillin susceptible (MSSA).

Out of 159 isolates, $21.38 \%$ subjects had S. aureus colonisation out of which $5.03 \%$ had MRSA colonisation (Table 3). All of these MRSA carriers were detected in the nursing staff. The carriage

Table 4: Sex wise distribution of nasal carriage of $S$. aureus and MRSA among various healthcare workers $(n=34)$

\begin{tabular}{|c|c|c|c|c|c|}
\hline \multirow[t]{2}{*}{$\begin{array}{l}\text { Healthcare } \\
\text { workers }\end{array}$} & \multirow[t]{2}{*}{$\begin{array}{l}\text { No. of nasal } \\
\text { swabs collected }\end{array}$} & \multicolumn{2}{|c|}{$\begin{array}{c}\text { No of } S \text {. aureus } \\
\text { isolated (\%) }\end{array}$} & \multicolumn{2}{|c|}{$\begin{array}{l}\text { No. of MRSA } \\
\text { isolated (\%) }\end{array}$} \\
\hline & & Male & Female & Male & Female \\
\hline Doctors & 50 & $4(8)$ & $1(2)$ & 0 & 0 \\
\hline Nursing staff & 109 & $17(15.60)$ & 12 (11.01) & $6(5.50)$ & $2(1.83)$ \\
\hline \multirow[t]{2}{*}{ Total } & 159 & 21 (13.21) & 13 (8.18) & $6(3.77)$ & $2(1.26)$ \\
\hline & & 34 & & 8 & \\
\hline
\end{tabular}

Note: percentage is shown in parenthesis; S. aureus: Staphylococcus aureus; MRSA: methicillin-resistant Staphylococcus aureus

Table 5: Mupirocin minimum inhibitory concentration (MIC) of nasal isolates of $S$. aureus $(n=34)$

\begin{tabular}{|c|c|c|c|}
\hline S. No. & $\begin{array}{l}\text { Mupirocin MIC } \\
(\mu \mathrm{g} / \mathrm{ml})\end{array}$ & $\begin{array}{l}\text { No. of } S \text {. aureus } \\
\text { isolates }\end{array}$ & $\begin{array}{l}\text { No. of MRSA } \\
\text { isolates }\end{array}$ \\
\hline 1 & $\leq 0.125$ & 13 & 01 \\
\hline 2 & 0.25 & 11 & 03 \\
\hline 3 & 0.5 & 06 & 02 \\
\hline 4 & 1 & 03 & 01 \\
\hline 5 & 2 & 01 & 01 \\
\hline 6 & 4 & 00 & 00 \\
\hline 7 & 8 & 00 & 00 \\
\hline Total & & 34 & 08 \\
\hline
\end{tabular}

Note: S. aureus: Staphylococcus aureus; MRSA: methicillin-resistant Staphylococcus aureus; MIC: minimum inhibitory concentration rate of $S$. aureus too was significantly higher in nursing staff ie, $26.60 \%$ with MRSA carriage rate of $7.34 \%$. Professors/associate professors/assistant professors and resident doctors were found to have $S$. aureus nasal carriage rate $16.67 \%$ and $7.89 \%$ respectively with no MRSA carriage. The MRSA carriage rate was $5.5 \%$ and $1.83 \%$ in male and female nursing staff, respectively (Table 4).

For $S$. aureus, mupirocin MIC $\leq 4 \mu \mathrm{g} / \mathrm{mL}$ is considered as susceptible. MIC $8-256 \mu \mathrm{g} / \mathrm{mL}$ is considered as intermediate resistant and MIC $\geq 512$ $\mu \mathrm{g} / \mathrm{mL}$ is considered as resistant. All $S$. aureus isolates had MIC $\leq 4 \mu \mathrm{g} / \mathrm{mL}$ for mupirocin, indicating mupirocin susceptibility of all the isolates (Table 5). Further, as many as $13 \mathrm{~S}$. aureus and 1 MRSA isolate had MIC $\leq 0.125 \mu \mathrm{g} / \mathrm{mL}$ and $11 \mathrm{~S}$. aureus and 3 MRSA isolates had MIC $\leq 0.25 \mu \mathrm{g} / \mathrm{mL}$.

\section{Discussion}

S. aureus is a common component of the skin flora, and $30 \%$ to $50 \%$ of healthy adults are colonised with it at any given time. The primary site of colonisation of $S$. aureus in humans are the anterior nares. ${ }^{2}{ }^{29}$ Hospital workers have higher rates of MRSA nasal colonisation than the general population. ${ }^{30}$ In the present study $21.38 \%$ subjects had $S$. aureus colonisation. Among HCWs around the globe, the nasal carriage rates of $S$. aureus have been reported at $14 \%$ in Nigeria, $27.5 \%$ in Turkey, $31.1 \%$ in Iran, 33.4 \% in France and $39.3 \%$ in Spain. ${ }^{31}$ The growing problem in India is that MRSA prevalence has increased from $12 \%$ to $80.83 \%{ }^{23}$

Out of a total of 159 subjects (50 doctors and 109 nursing staff) $S$. aureus and CoNS appeared in 34 and 125 samples respectively. Dual colonisation of $S$. aureus and CoNS was observed in 10 samples. However, no dual isolation was observed in a study conducted by Vinodhkumaradithyaa et $\mathrm{al}^{22}$ The prevalence of the $S$. aureus nasal carriage was higher among the male HCWs (13.21 $\%)$ than the female HCWs (8.18\%). Similar observation was reported by Rongpharpi et al. ${ }^{9}$ In the present study, the carriage rate of $S$. aureus was significantly higher in the nursing staff $26.60 \%$. Professors/associate professors/assistant professors and resident doctors were found to have $S$. aureus nasal carriage rate $16.67 \%$ and $7.89 \%$ respectively. Out of 34 S. aureus, $5.03 \%$ 
had MRSA colonisation. All of these MRSA carriers belonged to the nursing staff with MRSA carriage rate of $7.34 \%$. Similar studies from Barabanki, Uttar Pradesh reported $81 \%$ Staphylococcus, $48 \%$ S. aureus and $14 \%$ MRSA colonization. ${ }^{12}$ However, Bhatiani et al reported $39 \%$ and $15 \%$ carriage rates of S. aureus and MRSA in Rama Medical College, Hospital and Research Center, Kanpur which is similar to the findings presented here. ${ }^{32}$ Shobha et al found none of the healthcare workers colonised with $S$. aureus $s^{33}$ while a study from south India showed $9.3 \%$ S. aureus colonization. ${ }^{34}$

In the present study, on MRSA detection using oxacillin disc diffusion, cefoxitin disc diffusion and MIC of oxacillin by E-test, 8 (23.53\%) isolates were found to be MRSA. In this study, $8 \mathrm{~S}$. aureus isolates that were resistant to both cefoxitin and oxacillin had oxacillin MIC value $\geq 4 \mu \mathrm{g} / \mathrm{mL}$ and 26 isolates that were sensitive to both oxacillin and cefoxitin had MIC values $\leq 2 \mu \mathrm{g} / \mathrm{mL}$. Oxacillin screen agar could detect only $6(17.65 \%)$ isolates instead of 8 detected by the other three methods. Hence it is recommended that all four methods should be used for detection of oxacillin resistance. Pramodhini et al found oxacillin disc diffusion method to be less sensitive for the detection of MRSA. ${ }^{35}$ Mohanasoundaram and Lalitha obtained $100 \%$ concordance in disc diffusion method and oxacillin MIC using agar dilution methods. $^{36}$

In the present study, $97.04 \%$ staphylococcal isolates and $100 \%$ S. aureus and MRSA were found to be resistant to penicillin G. Similar findings were observed by Bala et al and Bhatiani et al where penicillin was found to be $100 \%$ resistant to all strains of $S$. aureus, ${ }^{37,32}$ but Rongpharpi et al reported $90 \%,{ }^{9}$ Duran et al reported $92.8 \%,{ }^{38}$ Kandle et al reported $98.9 \%$ penicillin resistance. ${ }^{39}$ All the MRSA isolates were resistant to penicillin as reported by Agarwal et al. ${ }^{12}$ In the present study, ampicillin and co-amoxiclav showed a resistance of $31.95 \%$ and $37.28 \%$ for staphylococci and $55.88 \%$ and $67.65 \%$ for $S$. aureus. Out of 8 MRSA isolates, 6 (75\%) and 8 (100 $\%$ ) isolates were found to be resistant to ampicillin and co-amoxiclav respectively. Bhatiani et al has reported a $100 \%$ resistance to ampicillin, ${ }^{32}$ while $88.57 \%$ and $82.00 \%$ resistance to ampicillin by $S$. aureus isolates was observed by Rongpharpi et al and Jindal et al in studies conducted among HCWs respectively., ${ }^{90}$ Study conducted at a tertiary care hospital in Iran reported $89.4 \%$ resistance among MRSA. ${ }^{41}$

A total of $34.91 \%$ Staphylococcus isolates, 64.71 $\%$ S. aureus isolates and all MRSA isolates were resistant to cephalexin in the present study while $73.7 \%$ MRSA isolates were found to be resistant to cephalexin in a similar study. ${ }^{42}$ In the present study, $24.85 \%$ and $15.38 \%$ staphylococcal, $50 \%$ and $38.24 \%$ S. aureus, $87.50 \%$ and $75.00 \%$ MRSA isolates were resistant to gentamicin and netilmicin respectively. In studies by Hauschild et al and Schmitz et al, $24.4 \%$ and $23 \%$ resistance was shown in $S$. aureus isolates to the above aminoglycosides. ${ }^{43,44}$ In this study, of 34 S. aureus isolates, $38.24 \%$ were resistant to at least one of the two aminoglycosides tested. Hauschild et al reported that $38.1 \%$ S. aureus were resistant to one of the aminoglycosides tested. ${ }^{43}$

In the present study, $42.60 \%$ Staphylococcus isolates and $58.82 \%$ S. aureus isolates were resistant to ciprofloxacin. Lower incidence of resistance $(10.4 \%)$ was reported by Tahnkiwale et $\mathrm{al}^{45} 41 \%$ by Duran et $\mathrm{al}^{38}$ and $90 \%$ by a Mexican study on 211 isolates. ${ }^{46}$ In Europe resistance by region showed a $5.6 \%$ resistance in the northern, $6.2 \%$ in the central and $23.6 \%$ in the southern region. ${ }^{47}$ Resistance to ofloxacin was shown by $18.34 \%$ Staphylococcus isolates and $32.35 \%$ S. aureus isolates in this study. Levofloxacin resistance stood at $9.47 \%$ and $11.76 \%$ for Staphylococcus and $S$. aureus isolates, respectively. However, $87.50 \%, 75.00 \%$ and $12.50 \%$ MRSA isolates showed resistance to ciprofloxacin, ofloxacin and levofloxacin, respectively. In contrast, Agarwal et al reported $50 \%$ MRSA isolates resistant to ciprofloxacin and $21.4 \%$ for levofloxacin. ${ }^{12}$

Erythromycin-resistant Staphylococcus often exerts cross resistance to other macrolides, lincosamide and streptogramin type $\mathrm{B}\left(\mathrm{MLS}_{\mathrm{B}}\right){ }^{48}$ In the present study erythromycin resistance was seen in $85.80 \%$ and $85.29 \%$ Staphylococcus and S. aureus isolates respectively. However, a lower resistance to erythromycin ranging between $66.66 \%$ and $67.9 \%$ has been observed by Bhatiani et al, ${ }^{32}$ Bala et $\mathrm{al}^{37}$ and Kausalya et al. ${ }^{49}$ Clindamycin resistance was shown in $36.69 \%$ and $50 \%$ Staphylococcus and $S$. aureus isolates, respectively, while in a study by Verma et al, ${ }^{23}$ erythromycin and clindamycin resistance was found to be $52.8 \%$ and $48.28 \%$, respectively in $S$. aureus isolates. In this study, $25.44 \%$ Staphylococcus and $38.24 \%$ S. au- 
reus isolates respectively were tetracycline-resistant. A higher resistance was reported by Shittu and Lin and Duran et al who reported $55.9 \%$ and $35.6 \%$ resistance for $S$. aureus isolates, respectively. $^{38,50}$ In the present study, $75.00 \%$ (6/8) MRSA isolates were found to be resistant to tetracycline which is much higher as reported by Agarwal et al. ${ }^{12}$

During the 17-year period of the studies by Cuevas et al there was low resistance of $S$. aureus to cotrimoxazole in all the studies (0.5 to $2.1 \%$ ). ${ }^{51}$ In this study, $82.35 \%$ S. aureus isolates were resistant to cotrimoxazole while other studies conducted in India have reported a resistance of $63.84 \%,{ }^{23}$ $73.3 \%,{ }^{32} 46.1 \%,{ }^{22} 31.43 \%{ }^{9}$ and $57.1 \%{ }^{40}$ Present study showed that $87.50 \%$ (7/8) MRSA isolates were resistant to cotrimoxazole which correlates with the study by Mohanasoundaram and Lalitha showing $82 \%$ cotrimoxazole resistance among the MRSA isolates. ${ }^{36} \mathrm{~A}$ somewhat higher resistance was reported by Pulimood et al $(97.1 \%)^{52}$ while low resistance in MRSA isolates was reported by Agarwal et al (57 \%). ${ }^{12}$

In the present study, a total of $55.62 \%$ (94/169) Staphylococcus isolates and $58.82 \%$ S. aureus isolates showed resistance to quinupristin dalfopristin. All the MRSA isolates (8/8, $100 \%)$ were found to be resistant to quinupristin dalfopristin, while in a study conducted by Kaur and Chate, only 5.56 $\%$ MRSA isolates were reported as resistant to quinupristin dalfopristin. ${ }^{53}$

In this study, $100 \%$ Staphylococcus and S. aureus isolates showed sensitivity to vancomycin. One MRSA isolate showed resistance to vancomycin disc on AST. However, due to limited resources, further testing of this isolate by MIC testing of vancomycin using agar dilution method (recommended by CLSI) to determine it as vancomycin-resistant (VRSA), intermediate (VISA) or sensitive (VSSA) could not be carried out. In a similar study, conducted at Kasturba Medical College, Hospital, Mangalore, no vancomycin resistance was observed in MRSA isolates. ${ }^{54}$ Complete sensitivity to vancomycin of $S$. aureus isolates was reported by Anupurba et al and Datta et al. ${ }^{55,56}$ In 2003, Assadullah et al reported staphylococcal isolates with intermediate susceptibility to vancomycin in India. ${ }^{57}$ Tiwari and Sen reported two strains of VRSA in the northern parts of India. ${ }^{58}$ Sharma and Vishwanath studied 156 MRSA isolates which were susceptible to vancomycin by disc diffusion method but, the MIC of 18 isolates was $\geq 4 \mu \mathrm{g} / \mathrm{mL}$ (VISA). ${ }^{59}$

This study showed $100 \%$ susceptibility to linezolid and vancomycin. Vancomycin and linezolid were found to be the most sensitive drugs against $S$. aureus in studies by Agarwal et al and Bhatiani et al. ${ }^{12,32}$ Golan et al reported a significant trend in increased MRSA linezolid resistance from 2002 onwards. ${ }^{60}$ Linezolid, a member of the new oxazolidone class of antibiotics is highly active in vitro against MRSA and has excellent oral bioavailability and constitutes the drug of choice against MRSA infection, besides vancomycin. The present study supported this.

Resistance to mupirocin is being reported from across the globe with a prevalence of $0.5 \%$ in $\mathrm{Ni}-$ geria to $14.6 \%$ in India. ${ }^{50,61}$ Rapid resistance to mupirocin has been reported among some strains of $S$. aureus isolated from various hospitals. In the present study of 34 S. aureus isolates, sensitivity to mupirocin was $88 \%$ with isolates having MIC < $0.5 \mu \mathrm{g} / \mathrm{mL}$. Mohajeri et al reported $100 \%$ sensitivity to mupirocin in the nasal carriage isolates of the patients. ${ }^{62}$ Though mupirocin resistance was not seen in the $S$. aureus isolates in the study by Mohajeri et al, the MIC of $9.2 \%$ of the isolates was as high as $4 \mu \mathrm{g} / \mathrm{mL}$ which was very close to a low level resistance $(8 \mu \mathrm{g} / \mathrm{mL}){ }^{62}$ In the study by Saderi et al, 6 strains had MIC $>4 \mu \mathrm{g} / \mathrm{mL} .^{63}$ Abimanyu et al observed all MRSA isolates showed a high level mupirocin resistance and inducible clindamycin resistance. ${ }^{64}$

Agarwal et al reported that $4(2 \%)$ isolates were found to be mupirocin-resistant of which three isolates were high levels resistant. ${ }^{12}$ In the presence of mupirocin-resistant strains, treatment with mupirocin may be ineffective, especially with high-level resistance strains. Although low-level mupirocin-resistant strains can be controlled by normal dosage schedule of mupirocin, a few studies suggest that treatment failure may occur. This emphasizes the importance of identification of both high and low-level resistant strains. ${ }^{65-67}$

Simple preventive measures like hand washing, using a sterile mask, gown and avoiding touching one's nose during work, should be reinforced in all healthcare settings. This study reiterates the need for periodic surveillance, early and accurate detection and treatment of MRSA carriers. This 
should be accompanied with appropriate hospital infection control measures, to prevent the nasal carriage of MRSA in hospital healthcare workers.

\section{Conclusion}

In the present study, very high carriage rate was detected in the anterior nares which are also the commonest site for Staphylococcus colonisation. The results obtained from the antibiogram of Staphylococci, S. aureus and MRSA isolates from colonised HCWs showed the increase in rates of resistance against various antibiotics. The present study confirms for the first time the presence of MRSA in HCWs working in this hospital and demonstrates the prevalence of the antibiotic resistance amongst them. Vancomycin resistance in Staphylococcus species is beginning to emerge as a clinical threat, yet the attention it has received is scant and serves to underscore the seriousness of the problem.

A better understanding of these issues will be a key to help in the prevention and treatment of these infections in the future and in containing the spread of these from HCWs to patients and vice versa. All the HCWs should be periodically educated and trained in the maintenance of hygiene and infection control and the effects of the use or rather, the misuse of antibiotics.

\section{The limitations of the study}

The study enrolled HCWs from a single tertiary healthcare centre, however, to generalise the results multi-centric studies are required.

\section{Contribution of Authors}

MC was involved in planning, concept design and hypothesis generation, NA did data collection, AC did data assembly, literature review and manuscript writing, MB helped in statistical analysis, GP and VR helped in data interpretation and literature review, AT helped in manuscript writing and data visualisation. All the authors collaborated and finally approved the manuscript.

\section{Ethics Statement}

The authors are accountable for all aspects of the work in ensuring that questions related to the accuracy or integrity of any part of the work are appropriately investigated and resolved. The study was conducted in accordance with the Declaration of Helsinki (as revised in 2013). The study was approved by the Ethics Committee of the JLN Medical College, Ajmer (No 42954-85, dated 28-10-2016).

\section{Acknowledgements}

None.

\section{Conflict of interest}

None.

\section{References}

1. Karmakar A, Dua P, Ghosh C. Biochemical and molecular analysis of Staphylococcus aureus clinical isolates from hospitalized patients. Can J Infect Dis Med Microbiol 2016;2016:9041636. doi: 10.1155/2016/9041636.

2. Lowy FD. Staphylococcus aureus infections. N Engl J Med 1998 Aug 20;339(8):520-32.

3. Murray PR, Baron EJ, Jorgenson JH, Pfaller MA, Yolken RH, eds., ASM Press 2003. Manual of clinical Microbiology 8th Edition. Diagn Microbiol Infect Dis 2003 Dec;47(4):625-6.

4. U.S. Centres for Disease Control and Prevention. Antibiotic resistance threats in the United States, 2013. Centres for Disease Control and Prevention, US Department of Health and Human Services; 2013. [Cited: 5-Mar-2021]. Available from: https://www.cdc.gov/drugresistance/ pdf/ar-threats-2013-508.pdf.

5. Demir T, Coplu N, Esen B. Comparative analysis of phenotypic and genotypic detection of methicillin resistance among Staphylococcus aureus. Indian J Pathol Microbiol 2016;59(3):314-7.

6. Chambers HF. Tracking the spread of CMRSA. APUA Newsletter 2003;21(2):1-5.

7. Waldvogel FA. Staphylococcus aureus (including toxic shock syndrome). In: Mandell GL, Douglas RG, Bennett JE (eds.). Principles and Practice of Infectious Disease, 3rd ed. London: Churchill Livingstone; 1990. p 1489-1510.

8. Projan SJ, Novick RP. The molecular basis of pathogenicity. In: Crossley KB, Archer GL, eds. The Staphylococci in Human Diseases. London: Churchill Livingstone; 1997. p. 55-81.

9. Rongpharpi SR, Hazarika NK, Kalita H. The prevalence of nasal carriage of Staphylococcus aureus among healthcare workers at a tertiary care hospital in Assam 
with special reference to MRSA. J Clin Diagn Res 2013 Feb;7(2):257-60.

10. U.S. Centers for Disease Control and Prevention. Active bacterial core surveillance report, emerging infections program network, Methicillin-resistant Staphylococcus aureus; 2011. [Cited: 5-Mar-2021]. Available from: https://www.cdc.gov/abcs/reports-findings/survreports/mrsa11.html.

11. Khan Z, Faisal S, Hasnain S. The continuing threat of Methicillin resistant Staphylococcus aureus-past, present, future. Journal of Scientific Research 2010;40(2):31-4.

12. Agarwal L, Singh AK, Sengupta C, Agarwal. Nasal carriage of Methicillin- and Mupirocin-resistant S. aureus among healthcare workers in a tertiary care hospital. J Res Pharm Pract 2015;4(4):182-6.

13. Kluytmans J, van Belkum A, Verbrugh H. Nasal carriage of Staphylococcus aureus: epidemiology, underlying mechanisms, and associated risks. Clin Microbiol Rev 1997 Jul;10(3):505-20.

14. Duncan IBR, Collins AM, Neelin EM, Roy TE. Nasal carriage of Staphylococcus pyogenes by student nurses. Can Med Assoc J 1957 Dec1;77(11):1001-9.

15. Paul MO, Lamikanra A, Aderibigbe DA. Nasal carriers of coagulase positive staphylococci in a Nigerian hospital community. Trans R Soc Trop Med Hyg 1982;76(3):31923.

16. McAnally TP, Lewis MR, Brown DR. Effect of rifampin and bacitracin on nasal carriers of Staphylococcus aureus. Antimicrob Agents Chemother 1984;25(4):422-6.

17. Dan M, Moses Y, Poch F, Asherov J, Gutman R. Carriage of Methicillin-resistant Staphylococcus aureus by non-hospitalized subjects in Israel. Infection 1992;20:332-5.

18. Eveillard M, Martin Y, Hidri N, Boussougant Y, Joly-Guillou ML. Carriage of methicillin-resistant Staphylococcus aureus among hospital employees: Prevalence, duration, and transmission to households. Infect Control Hosp Epidemiol 2004;25:114-20.

19. Akoua Koffi C, Dje K, Toure R, Guessennd N, Acho B, Faye Kette H, et al. Nasal carriage of meticillin-resistant Staphylococcus aureus among healthcare personnel in Abidjan (Côte d'lvoire) Dakar Med 2004;49(1):70-4.

20. Cesur S, Cokca F. Nasal carriage of methicillin-resistant Staphylococcus aureus among hospital staff and outpatients. Infect Control Hosp Epidemiol 2004;25(2):169-71.

21. Mulqueen J, Cafferty F, Cormican M, Keane JD, Rossney A. Nasal carriage of meticillin-resistant Staphylococcus aureus in GPs in the West of Ireland. Br J Gen Pract 2007;57:811-3.

22. Vinodhkumaradithyaa A, Uma A, Srinivasan M, Ananthalakshmi I, Nallasivam P, Thirumalaikolundusubramanian P. Nasal carriage of methicillin-resistant Staphylococcus aureus among surgical unit staff. Jpn J Infect Dis 2009;62(3):228-9.

23. Verma S, Joshi S, Chitnis V, Hemwani N, Chitnis D. 2000. Growing problem of methicillin resistant staphylococci-Indian scenario. Indian J Med Sci 2000;54(12):535-40.

24. Baron EJ, Thompson RB. Specimen collection, transport and processing: bacteriology. In Versalovic J, Carroll KC, Funke G, Jorgensen, JH, Landry ML, Warnock DW. Eds. Manual of Clinical Microbiology. 10th Ed. Chapter 16. Washington, DC: ASM Press; 2011. p. 228-71.

25. Bauer AW, Kirby WM, Sherris JC, Turck M. Antibiotic susceptibility testing by a standardized single disk method. Am J Clin Pathol 1966;45(4):493-6.

26. Clinical and Laboratory Standard Institute (CLSI). Perfor- mance standards for antimicrobial susceptibility testing. CLSI document M100S. 26th Ed. Wayne, P.A. Clinical and Laboratory Standard Institute, USA; 2016.

27. Mathews AA, Thomas M, Appalaraju B, Jayalakshmi J. Evaluation and comparison of tests to detect methicillin resistant S. aureus. Indian J Pathol Microbiol 2010;53(1):79-82.

28. Anand KB, Agrawal P, Kumar S, Kapila K. Comparison of cefoxitin disc diffusion test, oxacillin screen agar, and PCR for mecA gene for detection of MRSA. Indian J Med Microbiol 2009;27(1):27-9.

29. van Belkum A, Melles DC, Nouwen J, van Leeuwen W, van Wamel W, Vos M, et al. Co-evolutionary aspects of human colonization and infection by Staphylococcus aureus. Infect Genet Evol 2009;9(1):32-47.

30. Godfrey ME, Smith IM. Hospital hazards of Staphylococcal sepsis. JAMA 1958;166:197-200.

31. Mahmoud AM, Albadawy HS, Bolis SM, Bilal NE, Ahmed AO, Ibrahim ME. Inducible clindamycin resistance and nasal carriage rates of Staphylococcus aureus among healthcare workers and community members. Afr Health Sci 2015;15(3):861-7.

32. Bhatiani A, Yadav S, Pal N, Chandna A. Prevalence of carriage of Methicillin resistance Staphylococcus aureus among Healthcare Workers in a Tertiary Care Center, Kanpur (U.P), India. Int J Curr Microbiol App Sci 2017;6(5):739-46.

33. Shobha KL, Rao PS, Thomas J. Survey of Staphylococcus isolates among hospital personnel, environment and their antibiogram with special emphasis on methicillin resistance. Indian J Med Microbiol 2005;23(3):186-8.

34. Shinde RV, Pawar SK, Mohite RV, Shinde AR, Duggu P. Study of nasal carriage of Staphylococcus aureus with special reference to Methicillin resistance among nursing staff. Arch Clin Microbiol 2016;7:1.

35. Pramodhini S, Thenmozhivalli PR, Selvi R, Dillirani V, Vasumathi A, Agatha D. Comparison of various phenotypic methods and mecA based PCR for the detection of MRSA. JCDR 2011(Suppl-2);5(7):1359-62.

36. Mohanasoundaram KM, Lalitha MK. Comparison of phenotypic versus genotypic methods in the detection of methicillin resistance in Staphylococcus aureus. Indian J Med Res 2008 Jan;127(1):78-84.

37. Bala K, Aggrawal R, Goel N. Prevalence and susceptibility pattern of MRSA colonization in a teaching tertiary care centre in India. J Infect Dis Antimicrob Agents 2010;27(1):33-8.

38. Duran N, Ozer B, Duran GG, Onlen Y, Demir C. Antibiotic resistance genes \& susceptibility patterns in staphylococci. Indian J Med Res 2012;135(3):389-96.

39. Kandle SK, Ghatole MP, Takpere AY, Hittinhalli VB, Yemul VL. Bacteriophage typing and antibiotic sensitivity pattern of Staphylococcus aureus from clinical specimen in and around Solapur (South Maharashtra). J Commun Dis 2003 Mar;35(1):17-23.

40. Jindal N, Malhotra R, Grover P, Singh S, Bansal R, Kaur S. Methicillin resistant Staphylococcus aureus (MRSA) in Malwa region of Punjab (North-West India). Indian J Med Res 2016;143(3):371-72.

41. Dibah S, Arzanlou M, Jannati E, Shapouri R. Prevalence and antimicrobial resistance pattern of methicillin resistant Staphylococcus aureus (MRSA) strains isolated from clinical specimens in Ardabil, Iran. Iran J Microbiol 2014;6(3):163-8.

42. Japoni A, Ziyaeyan M, Jmalidoust M, Farshad S, Alborzi 
A, Rafaatpour N, et al. Antibacterial susceptibility patterns and cross-resistance of methicillin resistant and sensitive Staphylococcus aureus isolated from the hospitalized patients in Shiraz, Iran. Braz J Microbiol 2010 Jul;41(3):567-73.

43. Hauschild T, Sacha P, Wieczorek P, Zalewska M, Kaczynska k, Tryniszewska E. Aminoglycosides resistance in clinical isolates of Staphylococcus aureus from a University Hospital in Bialystok, Poland. Folia Histochem Cytobiol 2008;46(2):225-8.

44. Schmitz FJ, Fluit AD, Gondolf M, Beyrau R, Lindenlauf E, Verhoef J, et al. The prevalence of aminoglycoside resistance and corresponding resistance genes in clinical isolates of staphylococci from 19 European hospitals. J Antimicrob Chemother 1999;43(2):253-9.

45. Tahnkiwale SS, Roy S, Jalgaonkar SV. Methicillin resistance among isolates of Staphylococcus aureus: antibiotic sensitivity pattern \& phage typing. Indian J Med Sci 2002;56(7):330-4.

46. Calderon-Jaimes E, Espinosa de los Monteros LE, Avila-Beltran R. Epidemiology of drug resistance: the case of Staphylococcus aureus and coagulase-negative staphylococci infections. Salud Publica Mex 2002;44(2):108-12.

47. Thomson CJ. The global epidemiology of resistance to ciprofloxacin and the changing nature of antibiotic resistance: a 10 year perspective. J Antimicrob Chemother 1999 Mar;43 Suppl A:31-40.

48. Peacock SJ. Staphylococcus. In Borriello SP, Murray PR, Funke G. Eds. Topley and Wilson's Microbiology and Microbial Infections. 10th Ed. London: Hodder Arnold; 2005. p. 771-832.

49. Kausalya, Kashid RA, Sangeetha S. Nasal carriage and antimicrobial susceptibility of Staphylococcus aureus, with special reference to methicillin resistance, in healthcare workers in a tertiary care hospital in south India. Sch Acad J Biosci 2015;3(8):720-4.

50. Shittu AO, Lin J. Antimicrobial susceptibility patterns and characterization of clinical isolates of Staphylococcus aureus in KwaZulu-Natal province, South Africa. BMC Infect Dis 2006;6:125.

51. Cuevas O, Cercenado E, Vindel A, Guinea J, Sanchez-Conde $\mathrm{M}$, Sanchez-Somolinos M, et al. Evolution of the antimicrobial resistance of Staphylococcus spp. in Spain: Five Nationwide Prevalence Studies, 1986 to 2002. Antimicrob Agents Chemother 2004;48(11):4240-5.

52. Pulimood TB, Lalitha MK, Jesudason MV, Pandian R, Selwyn J, John TJ. The Spectrum of antimicrobial resistance among methicillin resistant Staphylococcus aureus (MRSA) in a tertiary care centre in India. Indian J Med Res 1996 Apr;103:212-5.

53. Kaur DC, Chate SS. Study of Antibiotic Resistance Pattern in Methicillin Resistant Staphylococcus aureus with Special Reference to Newer Antibiotic. J Glob Infect Dis 2015;7(2):78-84.

54. M R, D'Souza M, Kotigadde S, Saralaya KV, Kotian MS. Prevalence of Methicillin resistant Staphylococcus aureus carriage amongst healthcare workers of critical care units in Kasturba Medical College Hospital, Mangalore, India. J Clin Diagn Res 2013;7(12):2697-700.

55. Anupurba S, Sen MR, Nath G, Sharma BM, Gulati AK, Mohapatra TM. Prevalence of methicillin resistant Staphylococcus aureus in tertiary referral hospital in eastern Uttar Pradesh. Indian J Med Microbiol 2003;21(1):49-51.

56. Datta P, Gulati N, Singla N, Vasdeva HR, Bala K, Chander J, et al. Evaluation of various methods for the detection of meticillin-resistant Staphylococcus aureus strains and susceptibility patterns. J Med Microbiol 2011 Nov;60(Pt 11):1613-6.

57. Assadullah S, Kakru DK, Thoker MA, Bhat FA, Hussain N, Shah A. Emergence of low level vancomycin resistance in MRSA. Indian J Med Microbiol 2003;21(3):196-8.

58. Tiwari HK, Sen MR. Emergence of vancomycin resistant Staphylococcus aureus (VRSA) from a tertiary care hospital from northern part of India. BMC Infectious Diseases 2006;6:156.

59. Sharma P, Vishwanath G. Study of vancomycin susceptibility in methicillin-resistant Staphylococcus aureus isolated from clinical samples. ATMPH 2012;5(3):178-180.

60. Golan Y, Baez-Giangreco C, O'Sullivan C, Snydman DR. Trends in vancomycin susceptibility among consecutive MRSA isolates. In: Abstracts of the Forty fourth Annual Meeting of the Infectious Diseases Society of America 2006; Toronto, Ontario, Canada, Alexandria. Virginia: Infectious Disease Society of America; Abstract LB-11. p. 238.

61. Gadepalli R, Dhawan B, Mohanty S, Kapil A, Das BK, Chaudhry R, et al. Mupirocin resistance in Staphylococcus aureus in an Indian hospital. Diagn Microbiol Infect Dis 2007;58(1):125-7.

62. Mohajeri P, Gholamine B, Rezaei M, Khamisabadi. Frequency of mupirocin resistant Staphylococcus aureus strains isolated from nasal carriers in hospital patients in Kermanshah. Jundishapur J Microbiol 2012;5(4):560-3.

63. Saderi H, Emadi B, Owlia P. Phenotypic and genotypic study of macrolide, lincosamide and streptogramin B (MLSB) resistance in clinical isolates of Staphylococcus aureus in Tehran, Iran. Med Sci Monit 2011 Feb;17(2):4853.

64. Abimanyu N, Murugesan S, Krishnan P. Emergence of methicillin-resistant Staphylococcus aureus ST239 with high-level mupirocin and inducible clindamycin resistance in a tertiary care center in Chennai, South India. J Clin Microbiol 2012;50:3412-3.

65. Hudson IR. The efficacy of intranasal mupirocin in the prevention of staphylococcal infections: a review of recent experience. J Hosp Infect 1994 Jun;27(2):81-98.

66. Walker ES, Vasquez JE, Dula R, Bullock H, Sarubbi FA. Mupirocin-resistant, methicillin-resistant Staphylococcus aureus: does mupirocin remain effective? Infect Control Hosp Epidemiol 2003;24(5):342-6.

67. Singh AK, Venkatesh V, Singh M. Mupirocin resistance in clinical isolates of Staphylococcus aureus in a tertiary care hospital set up in North India. Int J Med Res Health Sci 2013;2:840-7. 